\title{
Simulated Effects of Cropland Expansion on Summer Climate in Eastern China in the Last Three Centuries
}

\author{
Quansheng Ge, Jingyun Zheng, Xuezhen Zhang, and Fanneng He \\ Institute of Geographic Sciences and Natural Resources Research (IGSNRR), Chinese Academy of Sciences (CAS), 11A Datun Road, \\ Chaoyang District, Beijing 100101, China
}

Correspondence should be addressed to Xuezhen Zhang; xzzhang@igsnrr.ac.cn

Received 18 July 2013; Accepted 15 September 2013

Academic Editor: Xiangzheng Deng

Copyright (C) 2013 Quansheng Ge et al. This is an open access article distributed under the Creative Commons Attribution License, which permits unrestricted use, distribution, and reproduction in any medium, provided the original work is properly cited.

\begin{abstract}
To understand the effects of the land use/cover changes due to agricultural development on summer climate in Eastern China, four 12 -year simulations using the WRF-SSiB model were performed. We found that agricultural development resulted in warming and rainy effects. In the middle to lower reaches of the Yellow River and the Yangtze River, the warming effects were approximately $0.6^{\circ} \mathrm{C}$ and resulted from increased surface net radiation and sensible heat fluxes. In Northeast China, the warming effects were very small due to increases in latent heat fluxes which resulted from the extensive conversion from grassland to cropland. The rainy effect resulted from increases in convective rainfall, which was associated with a warming surface in certain areas of the Yellow River and Yangtze River and a large increase in the surface moisture flux in Northeast China. Conversely, in the middle to lower reaches of the Yellow River and the Yangtze River, the grid-scale rainfall decreased because the climatological northward wind, which is moist and warm, was partially offset by a southward wind anomaly. These findings suggest that the agricultural development left footprints not only on the present climate but also on the historical climate changes before the industrial revolution.
\end{abstract}

\section{Introduction}

Eastern China is affected by the Asian monsoon [1]. In this area, summer is the warmest and wettest season. The heat and rainfall in summer feed agriculture for human welfare. Therefore, the summer climate has crucial implications to the originations and development of agriculture in East China [2]. The agriculture in Eastern China potentially extends back thousands of years [3]. Agricultural development converts land cover from natural vegetation (e.g., forest, grassland, and wetland) to anthropogenic cropland. Such conversions may lead to changes in surface parameters, including albedo, emissivity, and roughness and therefore may have important climatic implications $[4,5]$. As a result, as a by-product of agricultural development, the summer climate might be modified. The current summer climate might therefore include a human dimension. Studying the effects of agricultural development would be valuable for understanding "natural" summer climate to improve our predictability of future scenarios.

Many studies attempted to use past history to reveal the effects of human-induced land cover changes (HLCCs) on regional climate [6]. According to the experimental design, these simulation-based studies can be classified into two categories. The first category focused on the climatic effects of the conversion from potential nature land cover to current human-dominated land cover. For example, Fu [7] reported a weakened East Asia Monsoon due to HLCC using two 3-month (June to August) simulations. Gao et al. [8] reported increased precipitation in southern China, reduced precipitation over Northern China, cooling along the Yangtze River, and warming in extreme southern China using two 15year simulations. The HLCC prescribed in these simulations occurred from the origination of agriculture to the present. Therefore, the climatic effects that were revealed in these simulations were actually the total effects of the last several thousand years.

The second category of simulations used historical land use/cover data, which was reconstructed using historical data, for example, population data, agriculture/tax inventories, and mathematics estimations. These simulations attempted to study climatic effects of HLCC along with agricultural development from one point in time to another. Wang et al. [9] 
carried out eight one-month (June) simulations using land use for 1700, 1750, 1800, 1850, 1900, 1950, 1970, and 1990, respectively, from the HYDE dataset [10]. In this study, warming effects corresponding to conversions from forests to grassland and cropland and cooling effects corresponding to the conversion from short grass to cropland were reported. Li et al. [11] carried out five two-year simulations using land use for 1700, 1800, 1900, 1950, and 1990, respectively, from the HYDE dataset [10]. The increased rainfall in the middle and lower reaches of the Yangtze River, Northwest China, and Northeast China and warming effect were simulated [11]. Li et al. [11] also reported that the conversion from natural vegetation to cropland amplified heat differences between the ocean and land, therefore, enhancing the East Asian Summer Monsoon. However, many studies have reported that the HYDE dataset has a low ability to exhibit regional HLCC due to the lack of highly accurate historical cropland area data at regional scales. These shortcomings may result in uncertainties in our understanding of the climatic effects of HLCC [12].

In this study, we attempted to improve our understanding of the effects of historical HLCC on summer climate in Eastern China. Unlike existing studies, this study used a new anthropogenic land use dataset. This dataset was created using local historical archives and experts' experiences. The new dataset reproduces HLCC that more closely resembles the real history compared to the HYDE dataset [13]. Through comparisons of the simulated climate using natural vegetation and using human-dominant land cover conditions for the middle 17 th century, early 19th century, and late 20th century, we studied the potential effects of HLCC in the last 300 years on the summer climate in Eastern China.

This paper is organized as follows. Section 2 introduces the model, historical land use dataset and experimental design. In Section 3, we present the simulated climatic effects of historical HLCC. Finally, in Section 4, the conclusions are presented and the associated uncertainties and future research directions are also discussed.

\section{Experimental Design and Method of Data Processing}

2.1. Model and Experimental Design. The simulations were performed using the next-generation weather research and forecasting (WRF) V3.4.1 model with the advanced research WRF (ARW) dynamics solver [14]. The simplified version of the simple biosphere model ( $\mathrm{SSiB})[15,16]$ was used to simulation the land processes and radiation, heat fluxes, and moisture fluxes from the surface to the atmosphere. In the coupled model, the atmosphere provides heat, rainfall/snowfall, and wind to the underlying land. The land surface state is updated after absorbing downward radiation and heat fluxes, rainfall/snowfall, and wind (momentum). Then, the land surface reflects shortwave radiation, emits long wave radiation, and provides sensible heat fluxes and latent heat (moisture) fluxes to the atmosphere. Moreover, the canopy height determines the surface roughness length and thus regulates the wind speed.
In the $\mathrm{SSiB}$, there are three soil layers and one canopy layer. In total, there are 12 vegetation types, including anthropogenic crops. The parameters for vegetation were created using a variety of sources. Among them, seasonally varying monthly values of the leaf area index and green leaf fraction are prescribed. The other parameters are invariant with season. The prescription of the crop vegetation type is different from that of other vegetation types. The vegetation cover, leaf area index, green leaf fraction, leaf orientation, and root length are varied according to the growing season, which is a function of latitude and time. The SSiB is able to simulate land process and land-atmosphere in East Asia and has been widely used to simulate regional climate in East Asia [17-19].

In total, we performed four 12-year (1980-1991) simulations using individual land use data, respectively. The control experiment (E2000, hereafter) used land use in 2000. Moreover, two simulations (E1661 and E1820) used land use data in 1661 and 1820, respectively. The last simulation (NATU) used natural vegetation. Except for the land use/cover data, the four simulations used exactly the same settings and physical parameterizations schemes. The simulation domain (Figure 1) with a central point of $38^{\circ} \mathrm{N}$ and $107^{\circ} \mathrm{E}$ has a horizontal resolution of $50 \mathrm{~km}$ (110 grid cells in the zonal direction and 130 grid cells in the meridional direction) and 28 vertical levels (up to $50 \mathrm{hPa}$ ) for the atmosphere. The physical parameterizations used in this study include the community atmospheric model (CAM3) radiative transfer scheme for shortwave and longwave [20], the Grell-Devenyi ensemble convective parameterization [21], the Yonsei University counter-gradient boundary layer turbulence transfer scheme [22], the 5-class mixed phase cloud microphysics scheme [23], and the SSiB for land surface processes [15, 16]. The simulations were initialized on May 1, 1980, and ended on December 31, 1991. The lateral boundary conditions, sea surface temperature (SST), and sea ice were provided by the NCEP/DOE Reanalysis II dataset (dataset no. ds091.0 from rda.ucar.edu), which has a spatial resolution of 2.5 degrees and a 6-hour time interval.

2.2. Approach for Preparing the Land Use/Cover Data. First, we created a natural vegetation map for the NATU run. Then, we created human-modified land cover maps for 1661, 1820, and 2000, for the E1661, E1820, and E2000 simulations, respectively, using contemporary cropland to replace corresponding natural vegetation. The natural vegetation map was created using the default land use/cover data from the coupled WRF-SSiB model and the potential natural vegetation (PNV) map from Zhang et al. [24]. We filled the cropland cells in the default land use/cover data of WRF$\mathrm{SSiB}$ with the corresponding vegetation from the PNV; the natural vegetation cells remained unchanged. A natural vegetation map (Figure 1) was obtained. This natural vegetation map was used for the NATU simulation. Moreover, this natural vegetation map was used as the basis for creating the human-modified land cover maps for 1661, 1820, and 2000. By replacing corresponding natural vegetation with contemporary anthropogenic cropland, the human-modified land cover maps in 1661, 1820, and 2000, were created. 

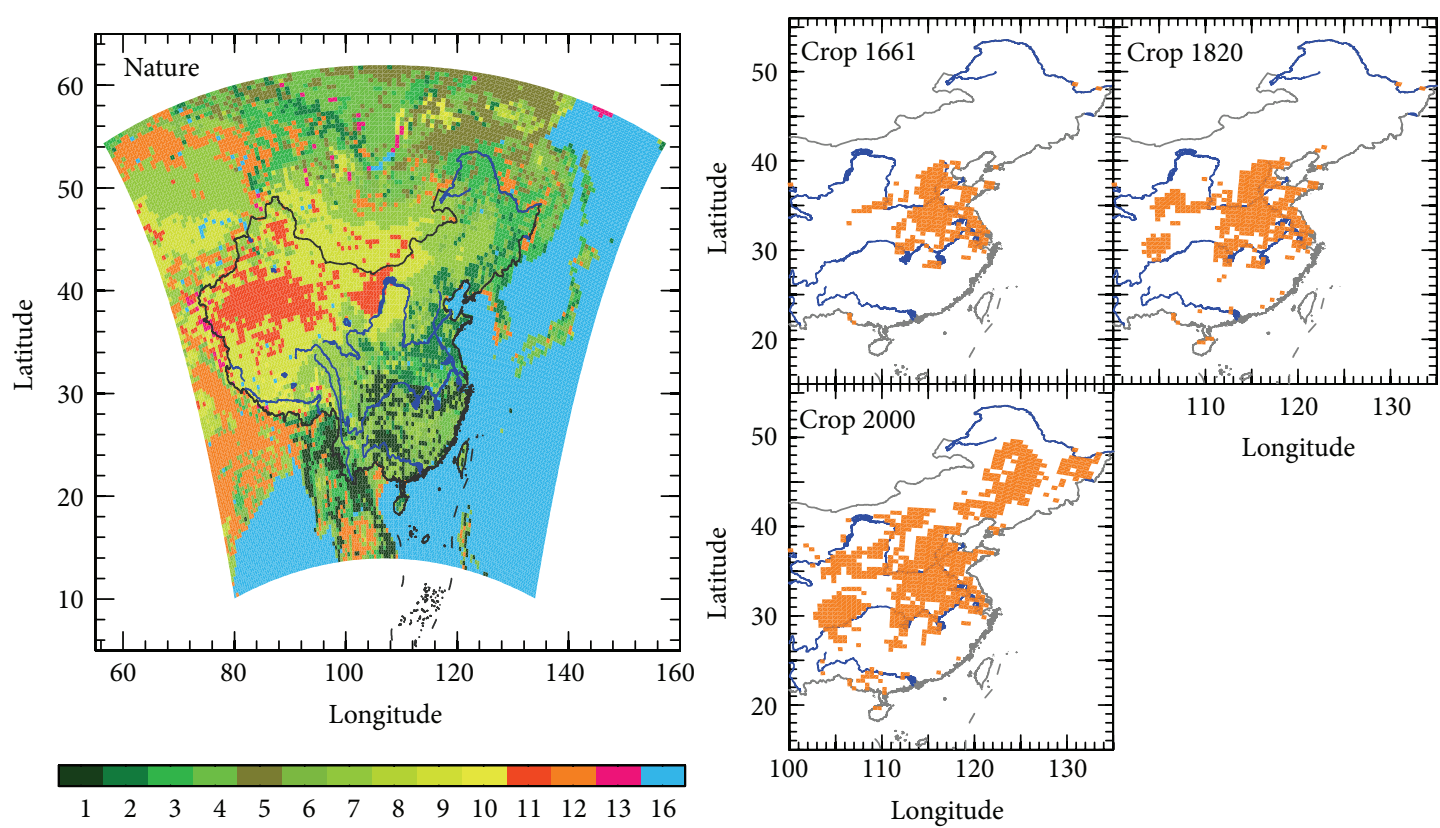

FIGURE 1: Natural vegetation in the simulation domain and cropland cells in Eastern China in 1661, 1820, and 2000 (the colorbar corresponds to the following: 1 broadleaf-evergreen tree; 2 broadleaf-deciduous trees; 3 broadleaf and needleleaf trees; 4 needleleaf-evergreen trees; 5 needleleaf-deciduous trees; 6 broadleaf trees with groundcover; 7 groundcovers only; 8 broadleaf shrubs with perennial groundcover; 9 broadleaf shrubs with bare soil; 10 broadleaf shrubs with ground cover; 11 bare soils; 12 croplands; 16 water bodies).

The human cropland data in 1661 and 1820 was given as a cropland area fraction with a cell size of $60 \mathrm{~km}$ by $60 \mathrm{~km}$. These data were originally created by collecting local historical cropland records and calibrating these records with governmental ground surveys in the early 20th century [25]. Lin et al. [26] developed a method for distributing the provincial cropland area into geographically explicit $60 \mathrm{~km}$ by $60 \mathrm{~km}$ grid cells. Lin's method comprehensively considers the effects of population and topography (elevation and slope) on agriculture. Because the original data were based on historical records for croplands and were comparable with the historical population census and agricultural tax, this dataset was shown to be closer to real history than the regional data from the HYDE and SAGE datasets [13]. To use these data in the E1661 and E1820 simulations, we redistributed the cropland area fraction for $60 \mathrm{~km}$ by $60 \mathrm{~km}$ cells into $50 \mathrm{~km}$ by $50 \mathrm{~km}$ WRF-SSiB cells using an area-weighted average. WRF-SSiB cells with more than half the grid area containing cropland were treated as cropland cells, while the others remained natural vegetation cells (Figure 1). The humanmodified land cover was created for E1661 and E1820 in this way.

The human cropland data for 2000 was also given in cropland area fraction, but for $1 \mathrm{~km}$ by $1 \mathrm{~km}$ pixels. This dataset was created using Landsat TM digital images and CBERS-1 (China-Brazil Earth Resources Satellite 1) data and local experts' knowledge which was valuable for improving the accuracy [27]. To use this high-resolution data in the E2000 simulation, we aggregated the $1 \mathrm{~km}$ by $1 \mathrm{~km}$ pixels into the $50 \mathrm{~km}$ by $50 \mathrm{~km}$ WRF-SSiB cells by calculating the mean cropland area fraction for the WRF-SSiB cells. Similar to the historical scenarios, the cells with more than half the grid area containing cropland were treated as cropland cells, while the others remained natural vegetation cells (Figure 1). This created the human-modified land cover for the E2000 simulation.

2.3. Method for Analyzing the Results. This paper focuses on the analysis of surface temperature and precipitation for summer (from June to August). We used the 0.5 degree by 0.5 degree gridded monthly daily-mean temperature dataset [28] and monthly precipitation dataset to evaluate our control simulation. The gridded data were produced using surface meteorological station data with topographic adjustment. The simulated $50 \mathrm{~km}$ resolution of temperature and precipitation from E2000 were interpolated to 0.5 degree by 0.5 degree grid cells through area weighting. We calculated the absolute values of grid cell-based differences between climatologic means from observations and a 1981-1991 simulation. Moreover, we calculated the spatial correlation between the simulation and observations as follows:

$$
r=\frac{\sum_{i=1}^{n}\left(x_{i}-\bar{x}\right) *\left(y_{i}-\bar{y}\right)}{\sqrt{\sum_{i=1}^{n}\left(x_{i}-\bar{x}\right)^{2} * \sum_{i=1}^{n}\left(y_{i}-\bar{y}\right)^{2}}} .
$$

Here, $r$ is the correlation coefficient, $x$ and $y$ denote observed and simulated climatology means, respectively, and $n$ represents the total number of grid cells in the study area.

Then, we calculated the differences (E1661, E1820, and E2000 minus NATU, resp.) for each cell to determine spatial pattern of differences. Because the four simulations used exactly the same settings and boundaries except for 

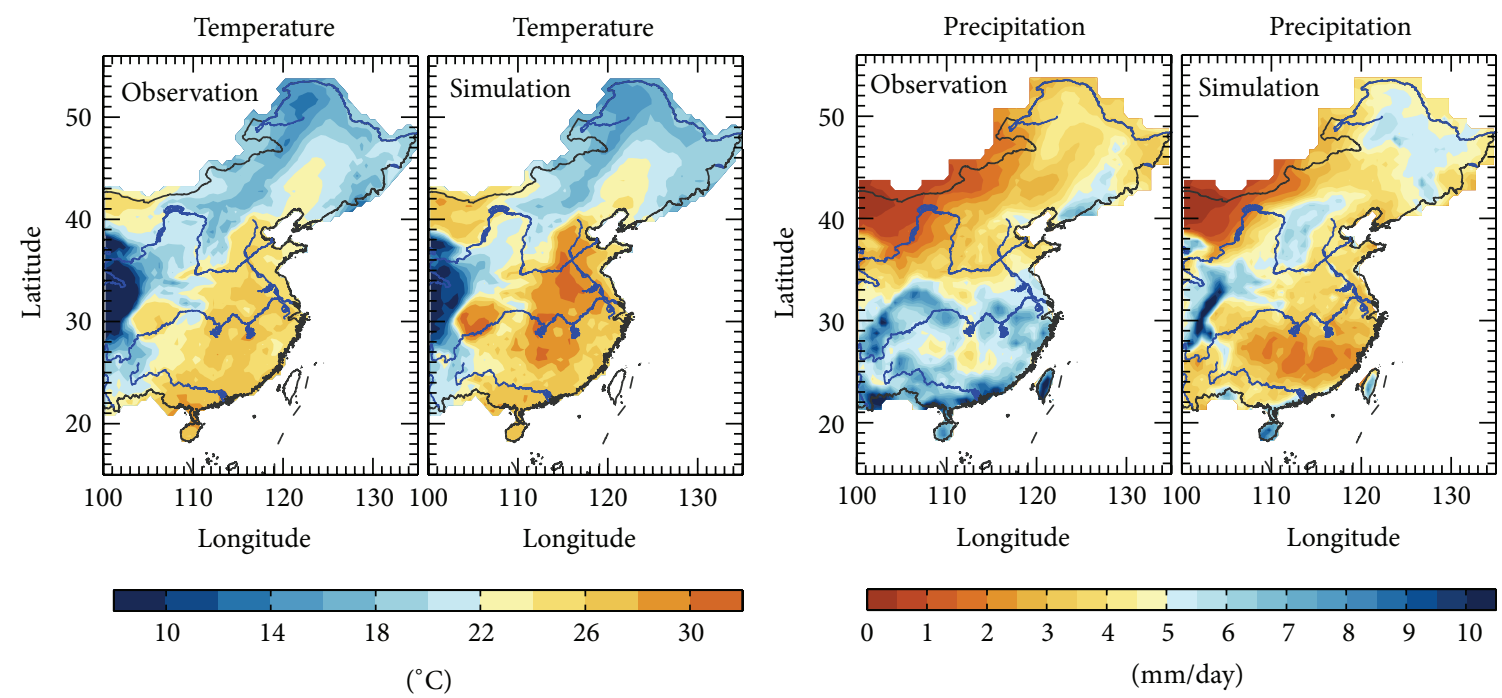

Figure 2: Ground observed and CTL simulated seasonal mean surface air temperature and precipitation for summer during the period 1981-1991.

the underlying land cover, these differences demonstrate the effects of land cover changes. In the analysis, we only used the mean simulation results from 1981 to 1991; the simulations for 1980 were treated as spin-up.

\section{Results}

3.1. Evaluation of the Control Simulation. Figure 2 shows the observed and E2000 simulated summer mean surface air temperature and summer rainfall from 1981 to 1991. A general agreement is found between the observations and the E2000 simulation, especially in regard to the geographical distribution. The spatial correlation coefficient between the simulation and observations is as high as 0.91 . This high correlation suggests that the coupled WRF-SSiB model is capable of reproducing spatial variability of climatological temperatures. The E2000 simulation also exhibits systematic biases. The regionally averaged root mean square error (RMSE) is $1.7^{\circ} \mathrm{C}$. Generally, the E2000 simulation has a warm bias. The largest warm bias $\left(3.6^{\circ} \mathrm{C}\right)$ primarily occurred in Tibet and the Huang-Huai-Hai Plain in North China.

Furthermore, general agreement in regard to the geographical distribution of rainfall was found. The spatial correlation between the simulation and observations is 0.66 . This suggests that the coupled WRF-SSiB model is able to capture the general spatial variability of summer rainfall. Large biases could be found as well. Less rainfall in South China characterized the bias. The low bias is approximately $40 \%$ of the observations.

Model bias has many sources, including boundary conditions, physical parameterizations, and mathematic expressions used in the dynamical framework. Diagnosing the sources of bias and reducing bias are very complicated and time consuming. In this study, we do not focus on the sources of bias. Instead, we focus on the differences between the simulations. The differences between the simulations might be a little affected by aforementioned bias, because most of the bias might be contained commonly in all of simulations, and therefore these bias might be largely removed through calculating the differences between the two simulations.

3.2. Effects on Temperature and Precipitation. Figure 3 shows the temperature effects of land cover changes induced by agricultural development. From 1661 to 1820 , and to 2000, effects were found along with the increase in cropland. On one hand, the area with warming effect extended spatially. On the other hand, the warming effect was also enhanced. In 1661, the warming effect could only be detected near the Huai River and the maximum warming effect was no higher than $0.8^{\circ} \mathrm{C}$. In 1820 , the detectable warming effects spread over the Huai River and the middle to lower reaches of the Yangtze River. The maximum warming effect reached up to approximately $1.2^{\circ} \mathrm{C}$ along the Huai River. In 2000, the area with detectable warming effects expanded to the entire middle to lower reaches of the Yangtze River and the northern to middle reaches of the Yellow River. The maximum warming effect moved to the Sichuan Basin and was as high as $1.8^{\circ} \mathrm{C}$. The areas with large warming correspond to land cover conversion from woodland to cropland. Such warming effect induced by the conversion from woodland to cropland was also reported by Wang et al. [9]. The warming effects were small in Northeast China where the conversion from grassland to cropland was dominant, even though tremendous agricultural development occurred in the 20th century. The slight warming shown here was different from the results shown previously that conversion from short grass to crops induced a slight cooling effect [9].

At the gridscale, the conversion from deciduous broadleaf forest to cropland was most extensive, accounting for $47 \%$ (1661) to $23 \%$ (2000) of cropland area. The mean warming was $\sim 0.25^{\circ} \mathrm{C}$. The conversion from grassland to cropland accounted for $14 \%$ (1661) to $30 \%$ (2000) and resulted in 


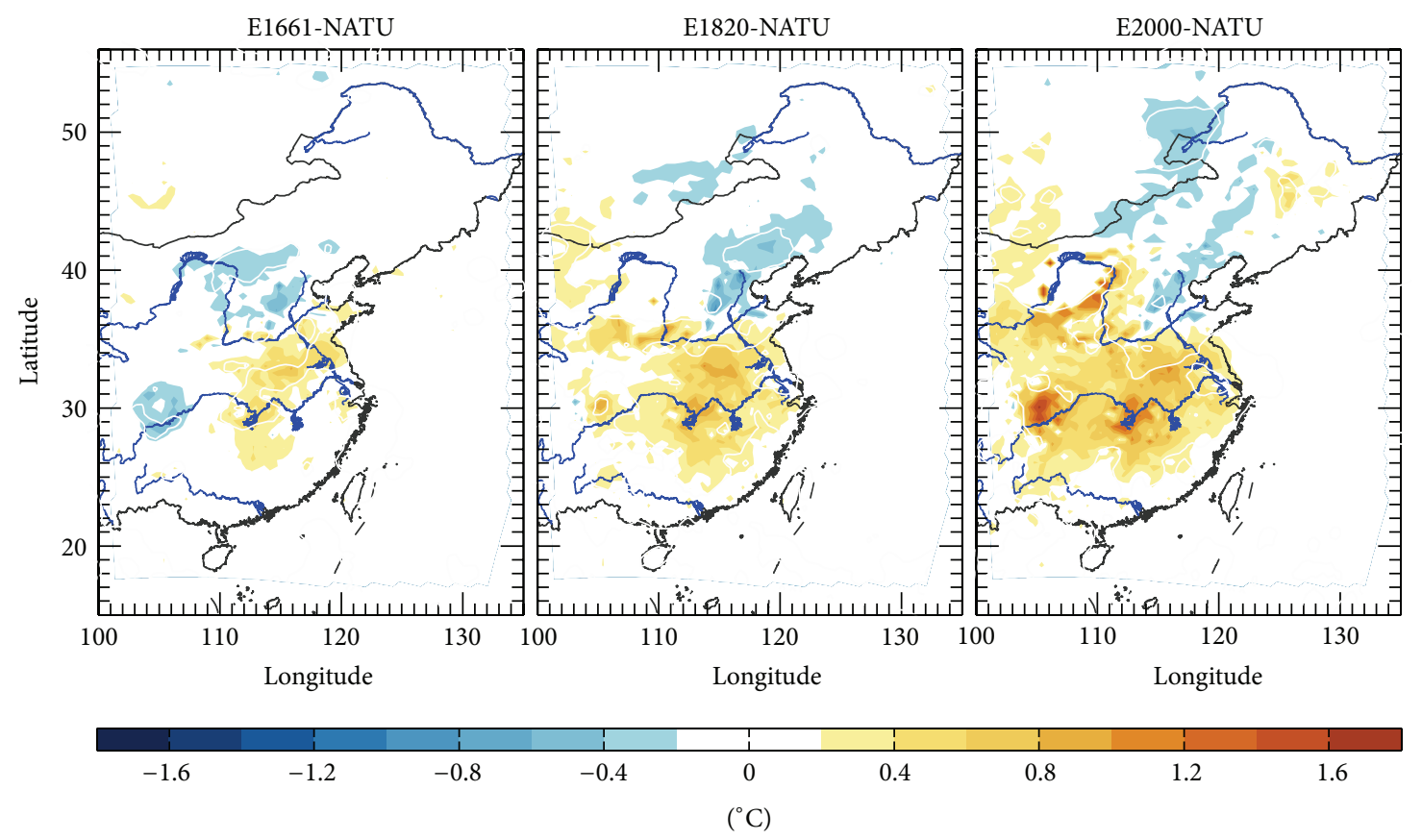

FIGURE 3: Changes in surface air temperature induced by land cover conversions from natural vegetation to cropland in 1661,1820 , and 2000.

a slight warming of $\sim 0.35^{\circ} \mathrm{C}$. The conversion from evergreen broadleaf forest to cropland and conversion from mixed broadleaf and needleleaf forest to cropland accounted for $10 \%-15 \%$ of cropland area. The mean warming caused by the conversion from evergreen broadleaf forest to cropland was as high as $0.5^{\circ} \mathrm{C}$. The mean warming caused by the conversion from mixed broadleaf and needleleaf forest to cropland was $\sim 0.2^{\circ} \mathrm{C}$. The conversion from broadleaf forest with grass to cropland accounted for a little more than $10 \%$ of cropland area. This conversion led to negligible changes in the surface air temperature.

Figure 4 illustrates the effects of land cover changes on rainfall. Generally, convective rainfall increased while the grid-scale rainfall decreased. With the expansion of cropland area from 1661 to 2000 , the areas with enhanced convective rainfall extended spatially. In 2000, the enhanced convective rainfall was found from Northeast China to South China. The largest increase in convective rainfall was as high as $1.8 \mathrm{~mm} /$ day and was found in the lower reach of the Yellow River. The increased convective rainfall spatially matched the aforementioned warming effects, except for Northeast China. This finding could be explained by our knowledge that a warm surface is good for convection.

Conversely, the grid-scale rainfall was broadly reduced, especially in the middle to lower reaches of the Yellow River. The spatial domain with decreased grid-scale rainfall was unvaried with the extension of the cropland area. However, the amplitude of the reductions increased gradually with the extensions of cropland area from 1661 to 2000 . The maximum reduction in grid-scale rainfall was $\sim 1.0 \mathrm{~mm} /$ day. Meanwhile, in Northeast China, a slight increase in grid-scale rainfall was found.
The amplitude of the enhancement in total rainfall increased and the areas with the largest increase moved spatially from 1661 to 2000 (Figure 4). In 1661, the largest increase $(\sim 0.8 \mathrm{~mm} /$ day) occurred along the Yangtze River. In 1820, the largest increase $(\sim 1.2 \mathrm{~mm} /$ day $)$ moved to the lower reach of the Yellow River. Lastly, in 2000, the largest increase ( $1.8 \mathrm{~mm} /$ day) moved northward to the Northeast China.

3.3. Effects on the Surface Energy Budget and Circulation. To understand the changes in temperature and rainfall, we analyzed changes in the surface energy budget and atmospheric circulation. Figure 5 shows the changes in the energy budget at the surface. Clearly, in agricultural areas, the downward solar radiation increased while the reflected shortwave radiation by surface decreased. According to the aforementioned experimental design, moisture in the atmosphere is the main factor causing differences in the downward solar radiation between the simulations. The increased downward solar radiation suggests a dry atmosphere, which corresponds to the increase in rainfall. The decrease in the reflected shortwave radiation at the surface was caused by weakened albedo. The weakened albedo, on one hand, resulted from the conversion of natural vegetation to cropland, which was prescribed (see $[15,16]$ for details). On the other hand, it also partly resulted from increased rainfall and thus increased soil moisture because the wet soil has a lower albedo than a dry soil.

In 1661 and 1820, the areas with the largest increase $\left(\sim 20 \mathrm{~W} \mathrm{~m}^{-2}\right)$ of downward solar radiation occurred along the Huai River. From 1661 to 2000, the strength of the increase in downward solar radiation remained nearly constant. However, the spatial domain extended to the lower 

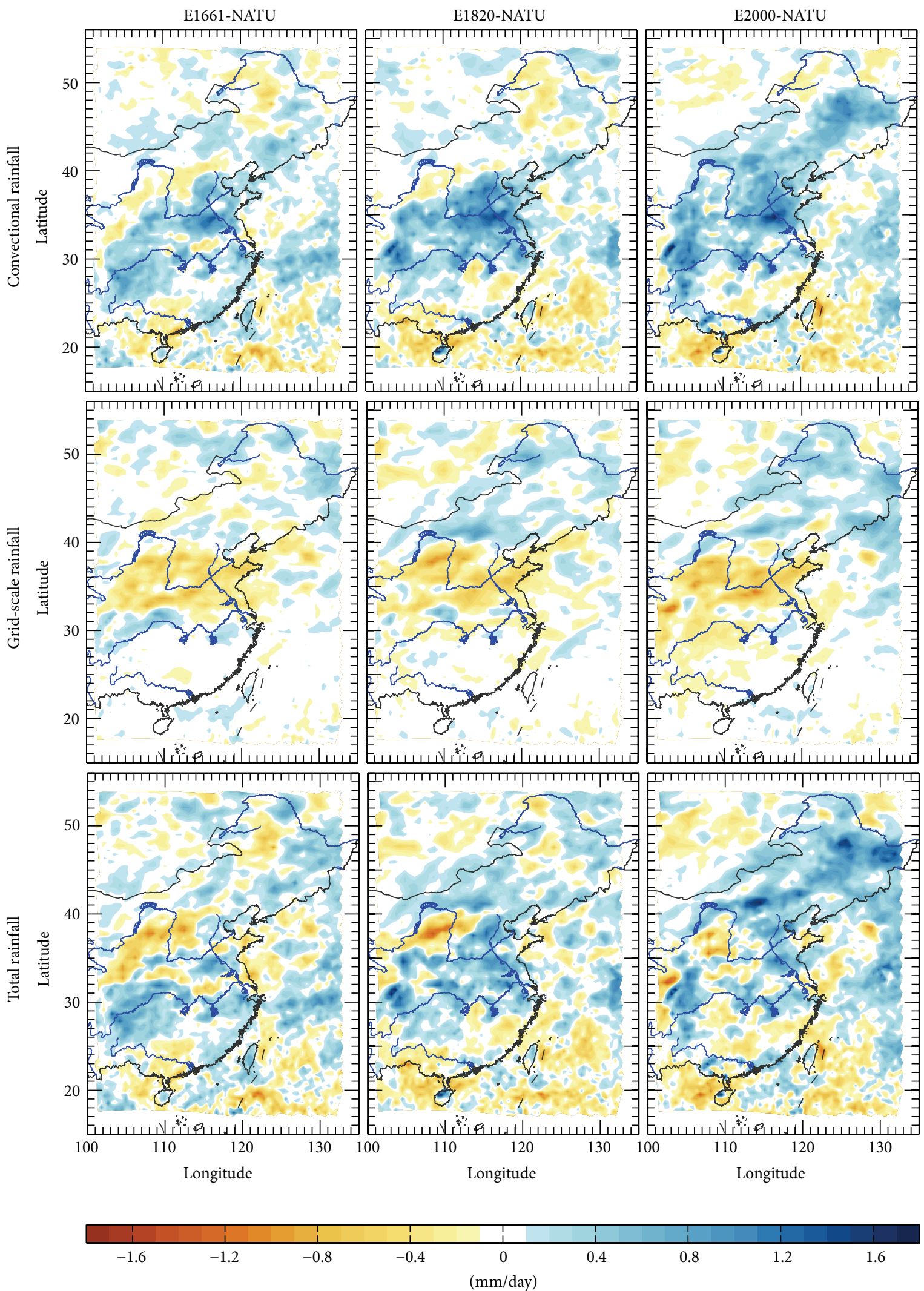

FIGURE 4: Changes in convective rainfall, grid-scale rainfall, and total rainfall induced by land cover conversions from natural vegetation to cropland in 1661, 1820, and 2000. 

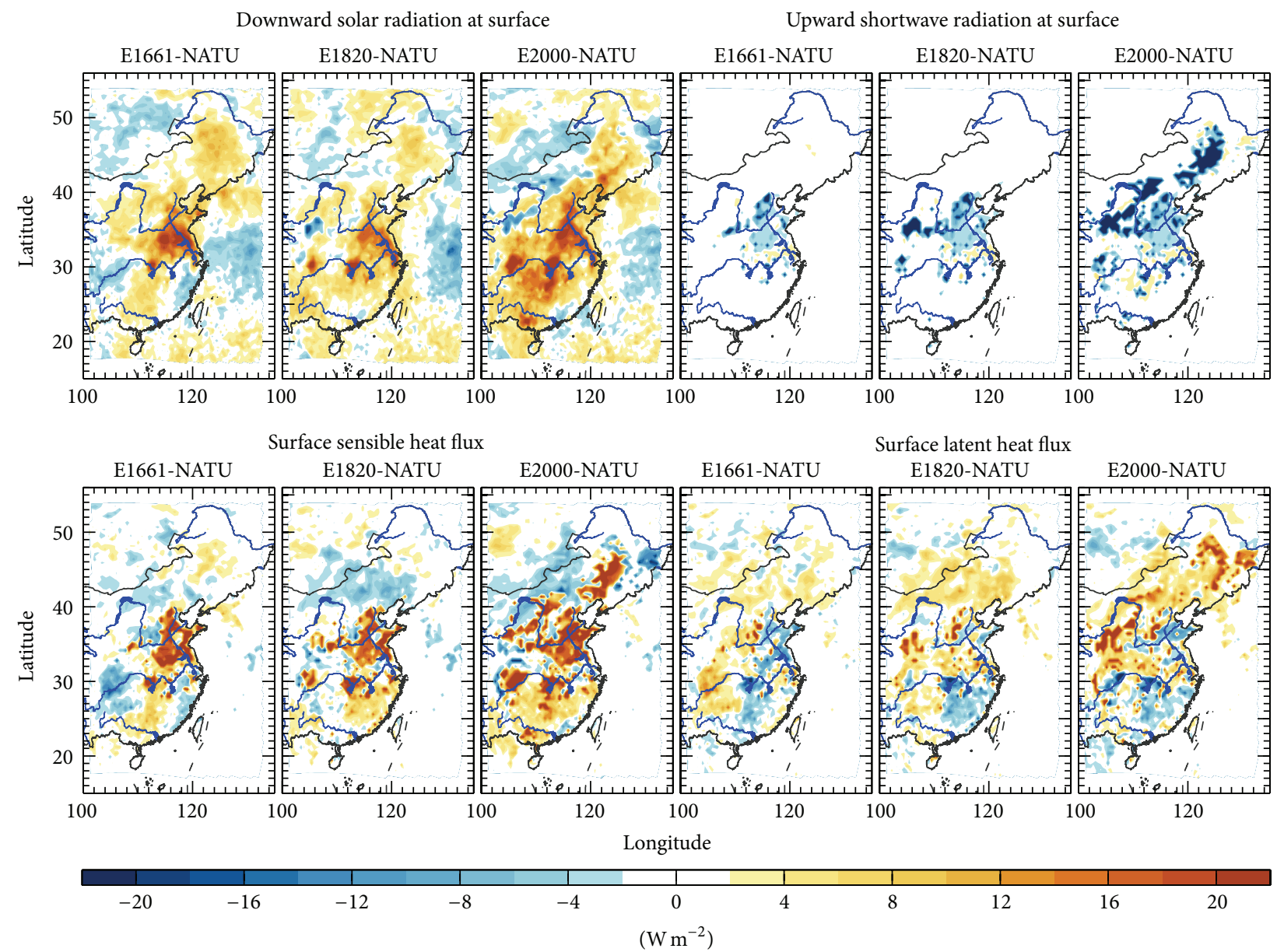

Figure 5: Changes in surface downward solar radiation, reflected shortwave radiation at the surface, surface sensible heat flux, and latent heat flux induced by land cover conversions from natural vegetation to cropland in 1661, 1820, and 2000.

reach of the Yangtze River. The decreased upward shortwave radiation spatially matched well with the agricultural areas. In the North China Plain, the decrease was approximately $-4 \mathrm{~W} \mathrm{~m}^{-2}$. Moreover, in Northeast China, the decrease was as large as $-20 \mathrm{~W} \mathrm{~m}^{-2}$. The increase in downward solar radiation and decrease in upward shortwave radiation jointly lead to increased surface net radiation.

Increased sensible heat fluxes in the agricultural area were found. The increase was as high as $20 \mathrm{~W} \mathrm{~m}^{-2}$. The changes in the latent heat fluxes varied geographically. Generally, in the lower reach of the Yellow River to the Yangtze River, the latent heat fluxes were slightly reduced. Furthermore, in Northeast China, the latent heat fluxes were broadly increased by as much as $20 \mathrm{~W} \mathrm{~m}^{-2}$. The largely increased sensible heat fluxes and small decreased latent heat fluxes explain the aforementioned surface warming in the lower reaches of the Yellow River and the Yangtze River, where the conversion from woodland to cropland was dominant. This finding is consistent with results reported by Wang et al. [9]. The extensive increase in the latent heat fluxes, which is able to partly offset the increased sensible heat-induced warming, explains the slight warming in Northeast China.
The increased latent heat fluxes implicate more moisture supply from the surface to the atmosphere, which is necessary for rainfall. Therefore, this finding also explains the enhanced convective rainfall in Northeast China.

Figure 6 shows the climatological wind and changes in wind for summer. From low $(750 \mathrm{hPa})$ to mid levels $(500 \mathrm{hPa})$ of troposphere, the northward wind is dominant across the Eastern China. This northward wind brings moisture from the southern oceans and leads to rainfall. Due to the changes in land cover, a cyclone occurred with a center in the East China Sea. Because the lower reaches of the Yellow River and the Yangtze River are located on the western side of the cyclone, there was a southward wind anomaly. Therefore, the climatological northward wind was partly offset by this southward wind anomaly. This finding implicates a weakened summer monsoon. The agricultural development-induced weakened summer monsoon had also been reported in previous studies $[7,8]$. There were also studies exhibiting enhanced summer monsoon [11], which is different from our findings. The decreased northward wind explains the decrease in grid-scale rainfall in the middle to lower reaches of the Yellow River and the Yangtze River. The formation of the cyclone also corresponded with the surface warming. 

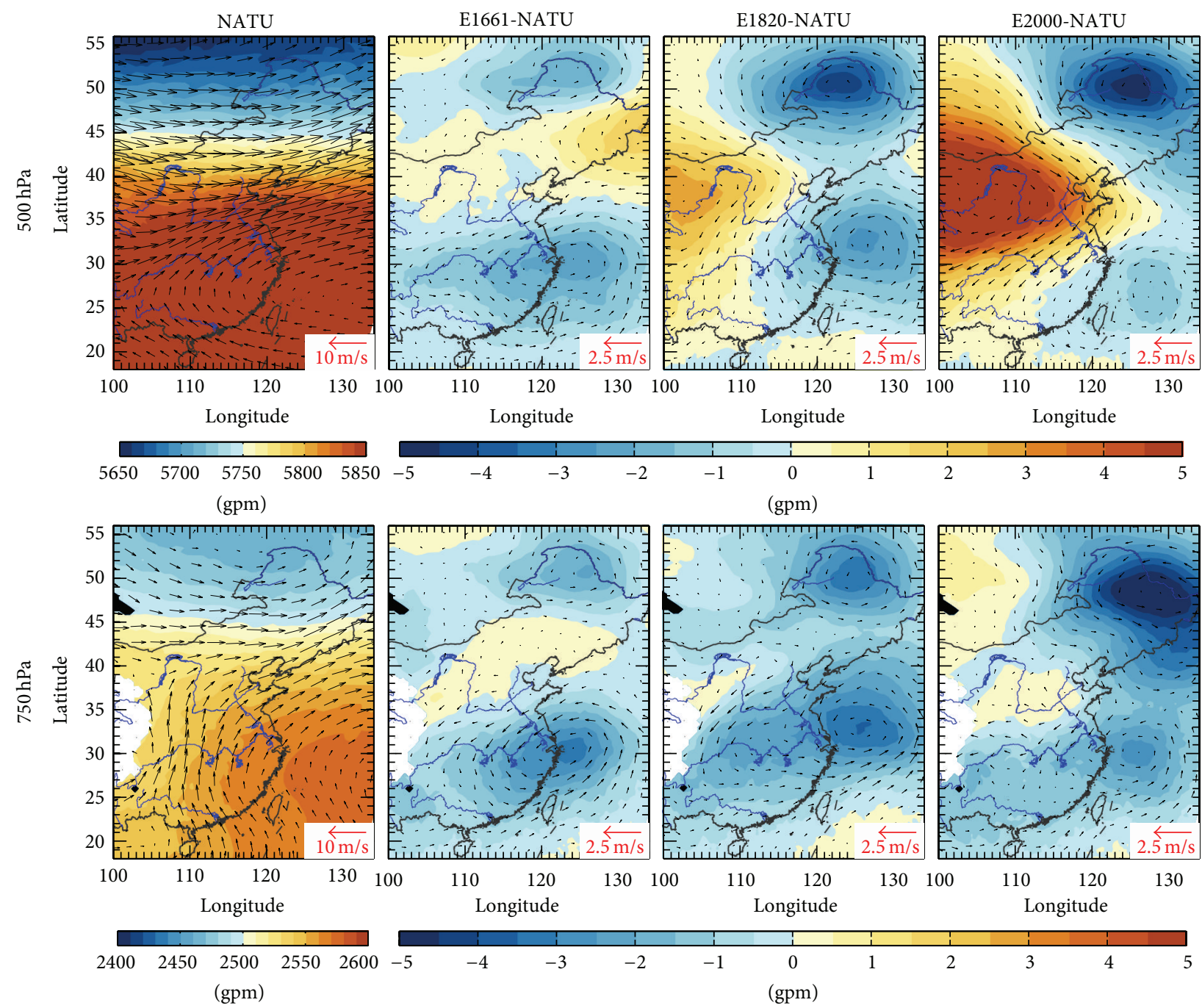

FIGURE 6: Height (color contours) and wind (arrows) at $500 \mathrm{hpa}$ and $750 \mathrm{hpa}$ underlying natural vegetation and the changes induced by land cover conversions from natural vegetation to cropland in 1661, 1820, and 2000.

The aforementioned results indicate that along the Yellow River and the Yangtze River, the changes in rainfall were closely related to the surface warming. The surface warming enhanced convective rainfall and concurrently weakened the grid-scale rainfall. In 1661 and 1820, increased convective rainfall was larger than the decrease in grid-scale rainfall. Therefore, the total rainfall increased. In 2000, the surface warming was much stronger than in 1661 and 1820 (Figure 3). However, the convective rainfall did not increase along with the surface warming. The grid-scale rainfall decreased with the surface warming. The total rainfall was therefore detected to have a small decrease (Figure 4). In Northeast China, the changes in total rainfall were predominantly determined by convective rainfall, which was closely related to the surface latent heat flux.

\section{Conclusion and Discussion}

This study simulated the effects of agriculture-induced land cover changes on surface air temperature and rainfall using the coupled WRF-SSiB model with historical land use data. Both warming and rainy effects were found. The warming effect was approximately $0.6^{\circ} \mathrm{C}$ and primarily located in the middle to lower reaches of the Yellow River and the Yangtze River, where woodland was converted into cropland. Moreover, the warming effects were weak in Northeast China, where grassland was converted into cropland. Near the Yellow River and the Yangtze River, the warming effect was mainly derived from increased surface net radiation and surface sensible heat flux. The surface warming resulted in more convection and therefore convective rainfall increased. Conversely, the grid-scale rainfall decreased because the northward wind that brings moisture to produce rainfall was partly offset by a southward wind anomaly. The southward wind anomoly was caused by western part of a cyclone that may also have been induced by the surface warming. In Northeast China where grassland was converted into cropland, the latent heat flux increased extensively. Due to increases in the latent heat flux, the surface warming was small. Moreover, the increased supply of moisture produced 
more convective rainfall. These findings demonstrate that in the last three centuries, the area experiencing warming and rainfall changes expanded along with the expansion of cultivated areas. Moreover, the warming effect in the cultivated areas was also strengthened.

This study confirms the idea that climatic effects of land cover changes vary with locations as noted by IPCC AR4. More importantly, this study demonstrates that during the past three centuries agricultural development may promote climate warming and the increases in convective rainfall in the Yellow River reach and the Yangtze River reach. From 1820 to 2000, tremendous agricultural development in Northeast China had little effect on temperature and lead to a potential increase in rainfall through increased latent heat fluxes. These findings are partly consistent with previous studies [7-9]. However, because this study only considered the conversion from natural vegetation to cropland, the results are different from findings in other studies [29], which focused on the climatic effects of agricultural management, for example, irrigation. This study may suggest that humans leave footprints not only on present climate change but also on historical climate change, before the industrial revolution.

Meanwhile, there are several relevant issues. Although the WRF model generally reproduces the major characteristics of temperature and precipitation variability, it contains biases, especially with rainfall. Preliminarily, the underestimated rainfall in South China may be associated with incorrect physical parameterization schemes and largely uncertain lateral boundaries conditions. Moreover, the surface parameters in the SSiB scheme, which represents a global mean condition, may be not applicable in Eastern China. To improve the performance of the WRF model, local parameters should be used. Additionally, we presented climatological differences using the large-scale circulation from 1980 to 1990. The simulation period was determined jointly using (1) data availability, (2) a long period with large climate variability, and (3) limited computer resources. It is worthy noting that the results did not precisely represent historical conditions because the local/regional climatic effects of HLCC may vary with large-scale circulation conditions. Therefore, nesting the WRF model into global model, such as CCSM or CESM model, to diagnose climatic effects of HLCC using historical circulation conditions is a potential avenue for future research. Moreover, it is important that the vegetation parameters, including leaf area index, canopy height, and canopy albedo, rely only on vegetation type that is prescribed by the modeller. However, these vegetation parameters also vary with climate conditions, including temperature, precipitation, and radiation. These variations may have feedbacks on climate. Therefore, it might be a potential research direction to consider both human-induced changes in vegetation types and vegetation dynamics together.

\section{Acknowledgments}

The NCEP/DOE Reanalysis II dataset for this study is from the Research Data Archive (RDA), which is maintained by the Computational Information Systems Laboratory (CISL) at the National Center for Atmospheric Research (NCAR). This research is supported by the National Natural Science Foundation of China (Grant no. 41001122) and the China Global Change Research Program (no. 2010CB950102) from the Ministry of Science and Technology of China.

\section{References}

[1] T. Zhou, H. H. Hsu, and J. Mastumoto, "Summer monsoons in East Asia, Indochina and the Western North Pacific," in Global Monsoon System: Research and Forecast, C. P. Chang, Y. Ding, N. C. Lau, R. H. Johnson, B. Wang, and T. Yasunari, Eds., pp. 43-72, World Scientific Publishing, Singapore, 2011.

[2] S. Piao, P. Ciais, Y. Huang et al., "The impacts of climate change on water resources and agriculture in China," Nature, vol. 467, no. 7311, pp. 43-51, 2010.

[3] D. J. Cohen, "The beginnings of agriculture in china: a multiregional view," Current Anthropology, vol. 52, supplement 4, pp. S273-S293, 2011.

[4] P. A. Dirmeyer, D. Niyogi, N. de Noblet-Ducoudré, R. E. Dickinson, and P. K. Snyder, "Impacts of land use change on climate," International Journal of Climatology, vol. 30, no. 13, pp. 1905-1907, 2010.

[5] R. Mahmood, R. A. Pielke, K. G. Hubbard et al., "Land cover changes and their biogeophysical effects on climate," Internal Journal of Climatology, 2013.

[6] J. Zheng, S. Lin, and F. He, "Recent progress in studies on land cover change and its regional climatic effects over China during historical times," Advances in Atmospheric Sciences, vol. 26, no. 4, pp. 793-802, 2009.

[7] C. Fu, "Potential impacts of human-induced land cover change on East Asia monsoon," Global and Planetary Change, vol. 37, no. 3-4, pp. 219-229, 2003.

[8] X. J. Gao, D. F. Zhang, Z. X. Chen, J. S. Pal, and F. Giorgi, "Land use effects on climate in China as simulated by a regional climate model," Science in China D, vol. 50, no. 4, pp. 620-628, 2007.

[9] H. Wang, A. J. Pitman, M. Zhao, and R. Leemans, "The impact of land-cover modification on the June meteorology of China since 1700, simulated using a regional climate model," International Journal of Climatology, vol. 23, no. 5, pp. 511-527, 2003.

[10] K. K. Goldewijk, "Estimating global land use change over the past 300 years: the HYDE database," Global Biogeochemical Cycles, vol. 15, no. 2, pp. 417-433, 2001.

[11] Q. Li, Y. Ding, and W. Dong, "A numerical simulation study of impacts of historical land-use changes on the regional climate in China since 1700," Acta Meteorologica Sinica, vol. 21, no. 1, pp. 9-23, 2007.

[12] P. Forster, V. Ramaswamy, P. Artaxo et al., "Changes in atmospheric constituents and in radiative forcing," in Climate Change 2007: The Physical Science Basis, S. Solomon, Ed., pp. 180-185, Cambridge University Press, Cambridge, UK, 2007.

[13] F. N. He, S. C. Li, and X. Z. Zhang, "Comparisons of reconstructed cropland area from multiple datasets for the traditional cultivated region of China in the last 300 years," Journal of Geographical Sciences, vol. 67, no. 9, pp. 1190-1200, 2012.

[14] W. C. Skamarock, J. B. Klemo, J. Dudhia et al., "A description of the advanced research WRF version 3," Tech. Rep. NCAR/TN475+STR, 2008.

[15] Y. Xue, P. J. Sellers, J. L. Kinter, and J. Shukla, "A simplified biosphere model for global climate studies," Journal of Climate, vol. 4, no. 3, pp. 345-364, 1991. 
[16] Y. Xue, F. J. Zeng, K. E. Mitchell, Z. Janjic, and E. Rogers, “The impact of land surface processes on simulations of the U.S. hydrological cycle: a case study of the 1993 flood usingthe SSiB land surface model in the NCEP Eta regional model," Monthly Weather Review, vol. 129, no. 12, pp. 2833-2860, 2001.

[17] Y. Xue, "The impact of desertification in the Mongolian and the Inner Mongolian grassland on the regional climate," Journal of Climate, vol. 9, no. 9, pp. 2173-2189, 1996.

[18] H. Liu and G. Wu, "Impacts of land surface on climate of July and onset of summer monsoon: a study with an AGCM plus SSiB," Advances in Atmospheric Sciences, vol. 14, no. 3, pp. 289308, 1997.

[19] Y. Xue, H.-M. H. Juang, W.-P. Li et al., "Role of land surface processes in monsoon development: East Asia and West Africa," Journal of Geophysical Research D, vol. 109, no. 3, Article ID D03105, 24 pages, 2004.

[20] W. D. Collins, P. J. Rasch, B. A. Boville et al., "Description of the NCAR community atmosphere model (CAM 3.0)," Tech. Rep. NCAR/TN-464+STR, 2004.

[21] S.-Y. Hong and H.-L. Pan, "Nonlocal boundary layer vertical diffusion in a medium-range forecast model," Monthly Weather Review, vol. 124, no. 10, pp. 2322-2339, 1996.

[22] S.-Y. Hong, J. Dudhia, and S.-H. Chen, "A revised approach to ice microphysical processes for the bulk parameterization of clouds and precipitation," Monthly Weather Review, vol. 132, no. 1, pp. 103-120, 2004.

[23] G. A. Grell and D. Dévényi, "A generalized approach to parameterizing convection combining ensemble and data assimilation techniques," Geophysical Research Letters, vol. 29, no. 14, pp. 381-38-4, 2002.

[24] X. Zhang and Editor Committee of Vegetation Map of China, Eds., Vegetation Map of China and its Geographic PatternIllustration of the Vegetation Map of the People's Republic of China (1:1000000), The Geongical Publishing House, Beijing, China, 2007.

[25] Q. Ge, J. Dai, F. He, J. Zheng, Z. Man, and Y. Zhao, "Spatiotemporal dynamics of reclamation and cultivation and its driving factors in parts of China during the last three centuries," Progress in Natural Science, vol. 14, no. 7, pp. 605-613, 2004.

[26] S. Lin, J. Zheng, and F. He, "Gridding cropland data reconstruction over the agricultural region of China in 1820," Journal of Geographical Sciences, vol. 19, no. 1, pp. 36-48, 2009.

[27] J. Y. Liu, M. L. Liu, D. F. Zhuang, Z. X. Zhang, and X. Z. Deng, "Study on spatial pattern of land-use change in China during 1995-2000," Science in China D, vol. 46, no. 4, pp. 373-384, 2003.

[28] Y. Xu, X. J. Gao, Y. Shen, C. H. Xu, Y. Shi, and F. Giorgi, "A daily temperature dataset over China and its application in validating a RCM simulation," Advances in Atmospheric Sciences, vol. 26, no. 4, pp. 763-772, 2009.

[29] W. Shi, F. Tao, and J. Liu, "Regional temperature change over the Huang-Huai-Hai Plain of China: the roles of irrigation versus urbanization," International Journal of Climatology, 2013. 

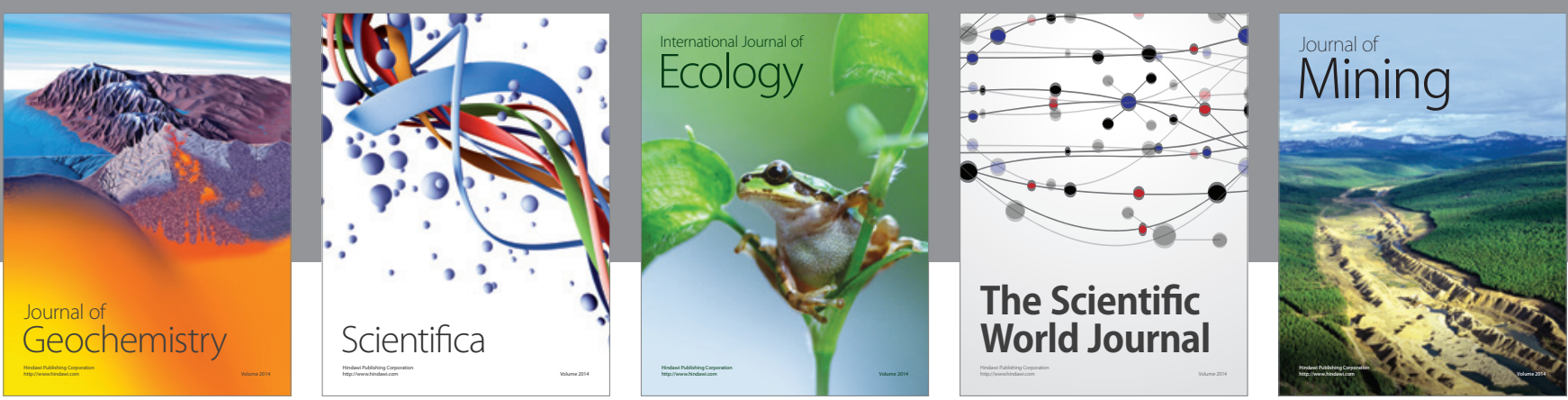

The Scientific World Journal
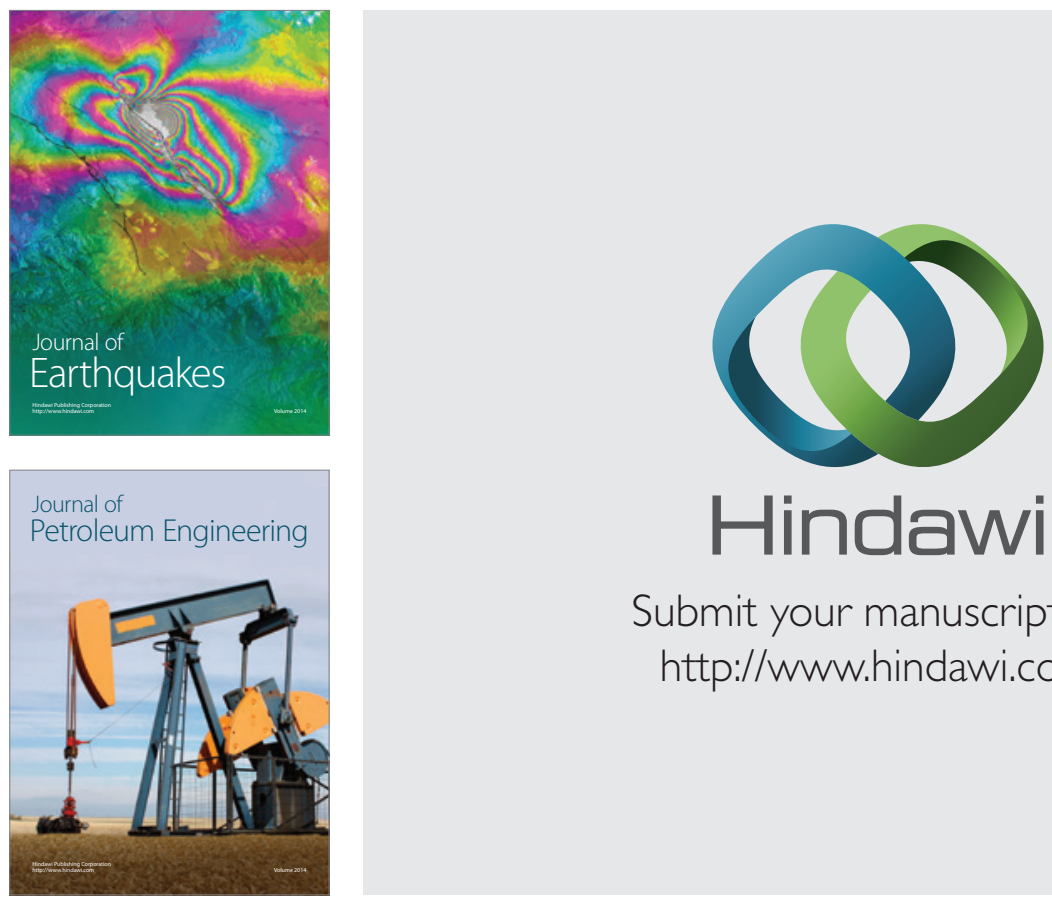

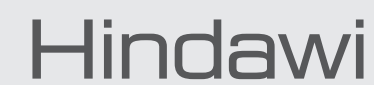

Submit your manuscripts at

http://www.hindawi.com
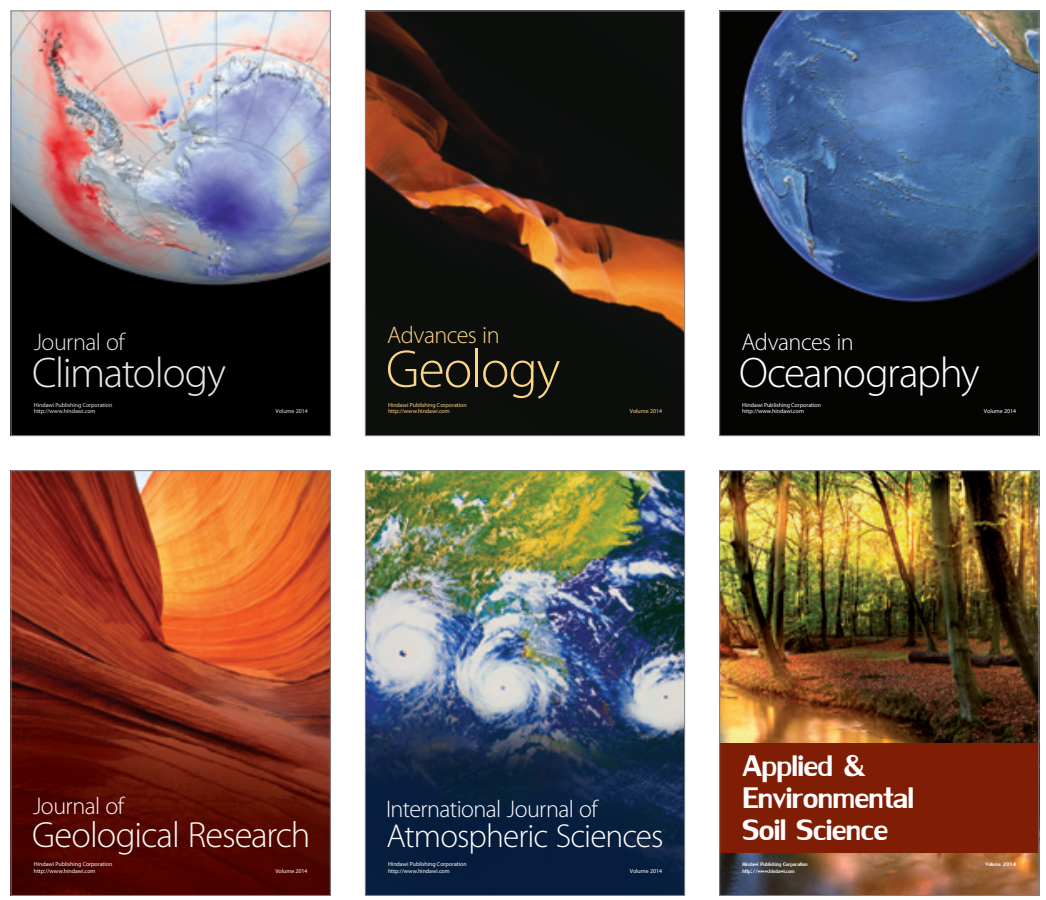
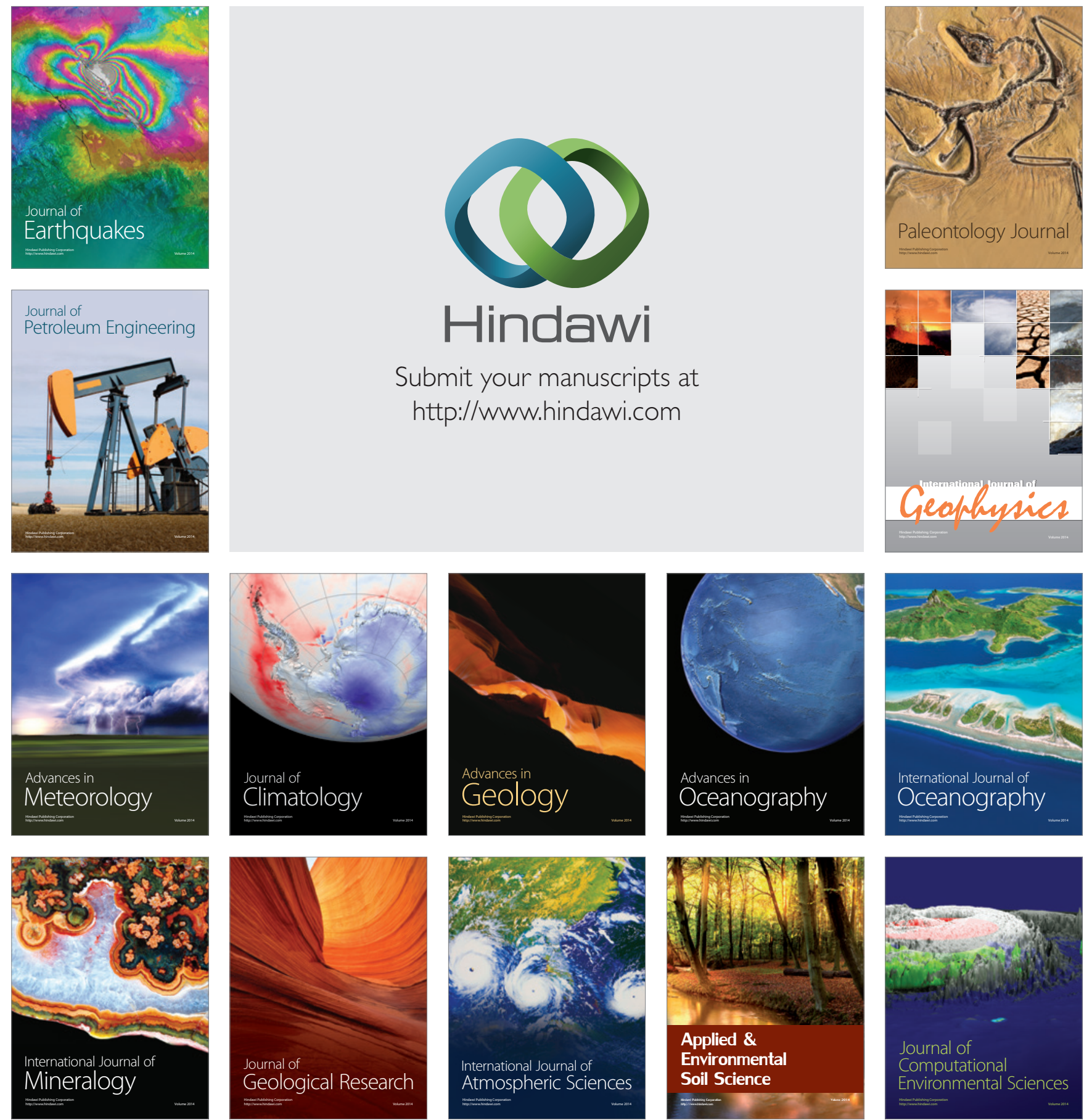